\title{
Red Blood Cell Distribution Width: A Predictor of Prognosis in Cardiac Surgery
}

\author{
Hengchao $\mathrm{Wu}^{1}$ \\ ${ }^{1}$ Affiliation not available
}

April 21, 2021

\begin{abstract}
Infectious endocarditis (IE) is a rare condition with an estimated yearly incidence of 3 to 10 cases per 100,000 people[1]. Its in-hospital mortality rate hovers around $18 \%$, with one-year mortality reaching up to $40 \%$ [2]. Although nearly $50 \%$ of IE cases now undergo surgical intervention, it does not appear to elevate the in-hospital mortality risk[3]. Wei et al conducted a study on the relationship between red blood cell distribution width (RDW) value and postoperative death of IE patients. Their most remarkable finding was the in-hospital mortality rate was significantly higher in the High RDW group(55.6\%vs.2.7\%)[4]. Their results suggestted that RDW may become a valuable biomarker for estimating poor postoperative outcome in patients with IE. RDW reflects the variable size of circulating red blood cells and is routinely used to narrow the differential diagnosis of anemia. However, many studies had revealed that RDW maybe a new prognostic marker to predict the cardiovascular event. The increased value have been always linked with inflammatory and oxidative states. Further studies are required to explore the mechanism for the relationship between the RDW and adverse clinical outcomes.
\end{abstract}

\section{Hosted file}

reply.pdf available at https://authorea.com/users/409227/articles/518990-red-blood-celldistribution-width-a-predictor-of-prognosis-in-cardiac-surgery 